\title{
INFLUENCE OF ETCHING AGGRESSIVENESS OF UNIVERSAL ADHESIVES ON LONGEVITY OF RESIN-DENTIN BONDING USING SELF-ETCH MODE
}

\author{
Hala Ragab*, Yassir Zyara** and Essam Osman***
}

\begin{abstract}
Objective: to assess micro-shear bond strength ( $\mu \mathrm{SBS}$ ) of two universal adhesives (UA) having two etching aggressiveness applied to dentin in a self-etch mode, immediately and after thermal ageing.

Methods: the occlusal enamel of twenty-eight sound human premolar teeth were removed to expose a flat dentin surface for bonding procedures. Teeth were randomly assigned to one of two groups according to the adhesive; the first group (Peak-Universal: PU) has intermediate etching aggressiveness $(1.2 \mathrm{pH})$ and the second group (All-Bond-Universal: $\mathrm{ABU}$ ) has ultra-mild etching aggressiveness $(3.2 \mathrm{pH})$. After bonding procedures as per manufacturer instructions, a nanohybrid composite resin was placed and light cured. All specimens were stored in demineralized water at $37^{\circ} \mathrm{C}$ for 24 hours. Half of the specimens were evaluated for $\mu$ SBS testing after 24 hours of water storage at $37^{\circ} \mathrm{C}$ and the other half were evaluated after thermal ageing using 10000 thermal-cycles and sixmonths water storage, then observed by SEM. $\mu$ SBS in (MPa) were compared with analysis of variance. Kolmogorov-Smirnov and Shapiro-Wilk tests were applied to assess normality of distributions $(P<0.05$ was considered as significant).
\end{abstract}

Results: PU showed statistically significant higher mean $\boldsymbol{\mu S B S}$ than AU, immediately and after thermal ageing. Thermal ageing and water storage did not significantly influence PU while bond degradation was significant in $\mathrm{AU}$.

Conclusion: with regard to the adhesive systems used in this study, when self-etch mode was used, $\mathrm{UA}$ with aggressive $\mathrm{pH}$ (intermediate) revealed better bonding effectiveness and stability against thermal aging and water storage than those with ultra-mild $\mathrm{pH}$.

Keywords: bond strength, dentin bonding, universal adhesives, self-etch, etching aggressiveness, thermal aging.

Clinical relevance: Self-etch mode has a positive effect on the dentin bond durability of universal adhesives, as was seen with the previous generation of self-etch adhesives.

* Associate professor, Division of Operative and Esthetic Dentistry, Faculty of Dentistry, Beirut Arab University, Lebanon (BDS, MSc, PhD, Operative and Esthetics, Cairo University, Egypt)

** Postgraduate Resident, Division of Operative and Esthetic Dentistry, Faculty of Dentistry, Beirut Arab University, Lebanon (BDS, University of Bagdad, Iraq)

*** Professor of Biomaterials, Faculty of Dentistry, Beirut Arab University, Lebanon (BDS, MSc, PhD, Dental Materials, Alexandia University, Egypt) 


\section{INTRODUCTION}

The principal challenge for contemporary dental adhesives is to provide user friendly, effective, and stable bonding protocol to dentin. In recent years, a new class has emerged in this arena, offering adaptability to several clinical situations and was promoted as universal adhesives (UA) and can be applied in a two-step total-etch or in a onestep self-etch mode (Munoz et al 2013). In order to serve this purpose, this category of bonding systems has incorporated acidic monomers that provide selective demineralization and promote chemical adhesion to dental structures which may improve bonding longevity (Hanabusa et al, 2012). This also could be significant in dentin bonding especially when they are used in self-etch mode. Adhesives used in the self-etch mode are designed to bond to dentin by simultaneous etching and resin replacement of the dissolved mineral component (Meerbeek et al 2003). For these versatile systems, the monomers used by different manufacturers vary in their chemistry and etching aggressiveness and thus UA were further classified according to their $\mathrm{pH}$ into: strong $(\mathrm{pH} \leq 1)$ allowing an interaction of some micrometers depth in dentin and enamel, intermediately strong or moderate $(1>\mathrm{pH}<2)$ allowing an interaction depth of $1-2 \mu \mathrm{m}$, mild $(\mathrm{pH} \geq$ 2) allowing an interaction depth of $1 \mu \mathrm{m}$, ultra-mild $(\mathrm{pH}>2.5)$ allowing nanometric interaction in depth (Ana Sezinando, 2014, Wagner et al, 2014).

The variation in the thickness of the interaction zone may result in different bonding effectiveness and behavior by time. Stronger $\mathrm{pH}$ adhesives create thicker hybrid zone with typical resin tags in dentin whereas milder $\mathrm{pH}$ adhesives create thinner hybrid zone and the smear plugs get slightly demineralized for subsequent resin infiltration (Van Meerbeek et al, 2011).

Its worth mentioning that the quality and thickness of the smear layer is influenced by the type of cutting instrument used in cavity preparation which may be significant when self-etch mode is used. Firmly-attached thick smear layer created by diamond burs may act as a physical barrier against infiltration and polymerization of monomers. Thus, the $\mathrm{pH}$ of acidic monomers in the UA maybe critical in order to dissolve the smear layer without demineralizing dentin surface and preserving some hydroxyapatite for chemical bonding (Wagner et al 2014). Additionally, the chemical composition of the monomers included in the adhesive formulation is important. Some of the available monomers contain phosphate, carboxylic acid, and alcohol groups. These functional monomers can promote wetting, demineralization, and ionic binding to the mineralized tooth substrate such as 10-methacryloyldecyl-di-hydrogen-phosphate (MDP). Adhesives containing MDP have been shown to create an 'acid-base resistant zone' that plays a key role in preventing secondary caries, sealing restoration margins and promoting restoration durability (Nikaido et al 2011, Matsui et al 2015).

The bonding effectiveness of restorative materials to tooth substrates have primarily been evaluated using microshear or microtensile bond strength tests. These tests provide valuable information regarding bond strength and the general characteristics of adhesive systems. However, failures in these tests are probably not representative of failures in intra-oral conditions which results from repetitive thermal, mechanical and chemical changes in the bonded interface over time. Thermal-cycling and long-term water storage combined with bond strength tests have been common methods for testing the in vitro degradation of restored teeth. Results before and after the degradation processes can be standardized and easily compared to previous reports (Poggio et al, 2014). Thermal-cycling simulates accelerated chemical degradation and contraction/expansion stresses as a result of the difference in coefficient of thermal expansion between tooth substrates and the restorative materials (Wagner et al, 2014; 
Farias et al, 2016). Thus, thermal-cycling can accelerate thermal degradation near the adhesive layers due to thermal stress; this is because of both the discrepancies between the thermal expansion rates of the substrates and the hydrolytic degradation caused by the water bath (Perdigão J, Swift 2015). However, the degradation mechanism that occurs near an adhesive during water storage is thought to be mainly related to the hydrolytic degradation of the resinous materials (Manfroi et al, 2016). Using combined methods for artificial aging may provide better insights into the in vivo performance and more realistic values for sustainable stresses (Costa et al, 2017).

The aim of this study was to assess micro-shear bond strength $(\mu \mathrm{SBS})$ of two universal adhesives (UA) having two etching aggressiveness (ultra-mild and intermediate $\mathrm{pH}$ ) applied to dentin in a self-etch mode, immediately and after 10000 cycles thermal ageing and six-months water storage. Additionally, to evaluate and observe the failure mode using scanning electron microscope (SEM).

The null hypothesis was that when self-etch mode is used, the etching aggressiveness of UA would not influence resin-dentin micro-sheer bond strength ( $\mu \mathrm{SBS})$ and the thermal-aging together with water storage would not influence the longevity of the bonded interface for the two tested materials.

\section{MATERIALS AND METHODS}

\section{Teeth selection}

Twenty-eight sound human premolar teeth were collected from the teeth bank at Faculty of Dentistry, Beirut Arab University according to the guidelines of the research and ethical committee. Teeth were disinfected in $0.5 \%$. The enamel part was sectioned using a diamond disc to expose mid-coronal dentin surface. The flat dentin surface was polished on wet 320-grit silicon-carbide paper for 60 seconds to standardize the smear layer and rinsed with distilled water for 30 seconds to remove the debris.

\section{Experimental design and specimen preparation}

Teeth were randomly divided into two groups $(\mathrm{n}=14)$ according to the universal adhesive system tested; one with intermediate $\mathrm{pH}$ value $(=1.2 ; \mathrm{PU})$ and the other one with ultra-mild $\mathrm{pH}(=3.2 ; \mathrm{ABU})$ . Both systems were applied in self-etch mode (SE). The adhesive systems were applied as per the manufacturer's instructions as shown in table (1). After the bonding procedures, hollow cylinders from a micro-bore rubber tubing with an internal diameter of $0.75 \mathrm{~mm}$ and a height of $4.0 \mathrm{~mm}$ were cut and placed on the adhesive surfaces. Two increments ( $2 \mathrm{~mm}$ thickness each) of a nanohybrid composite resin (Z250 XT, 3M ESPE, USA) were inserted into the tubing lumens and light polymerized for 40 seconds as per the manufacturer instructions. The tubing around composite cylinders were removed by gently cutting the tube into hemi- cylinders using a feather blade. During this procedure, caution was paid to avoid applying any stress to the bonded composite cylinders. Specimens were then stored in demineralized water at $37^{\circ} \mathrm{C}$ for 24 hours then subjected to $\boldsymbol{\mu S B S}$ testing and thermal-cycling and water aging.

\section{$\mu$ SBS testing and thermal-cycling}

Half of the specimens were assigned for immediate $\mu$ SBS testing while the other half were assigned for thermal-cycling. The specimens were held in a custom made attachment unit with the cut surface held perpendicular to the horizon. A sharp flat edge knife with a circular cut section matching the size of the prepared resin composite discs where attached to a universal testing machine (Instron 6022, Instron Limited, High Wycombe, UK), equipped with a sensitive load cell $(25 \mathrm{~kg})$ and the specimens were fractured at crosshead speed of $0.1 \mathrm{~mm} / \mathrm{sec}$. $\boldsymbol{\mu S B S}$ was evaluated by dividing the measured force $(\mathrm{N})$ by the cross section of the resin composite $(0.9 \mathrm{~mm}$ in diameter). Groups assigned for thermal aging were subjected to 10000 thermocycles at $\left(5-55^{\circ} \mathrm{C}\right)$ with a dwell time of 30 seconds 
TABLE (1) Adhesive types and application modes according to the manufacturer instructions

\begin{tabular}{|c|c|}
\hline sition & anufacturer instruction for application using self-etch strategy (SE) \\
\hline $\begin{array}{l}\text { peak LC bond), Ultradent Product Inc, South Jordan, } \\
\text { UT, USA) } \\
\text { Composition: Peak SE primer: ethyl alcohol, } \\
\text { methacrylic acid, 2-HEMA. Peak LC bond resin: ethyl } \\
\text { alcohol, 2-HEMA, chlorhexidine } \mathrm{pH}=1.2 \text { (moderate) }\end{array}$ & $\begin{array}{l}\text { 2. Application of the peak SE with microbruch for } 20 \text { s using } \\
\text { continuous scrubbing on dentin } \\
\text { 3. thin/dry for } 3 \mathrm{~s} \text { using air/water syringe or high-volume suction } \\
\text { directly over preparation } \\
\text { 4. Apply a puddle coat of peak LC bond with gently agitate for } 10 \mathrm{~s} \\
\text { 5. Thin/dry } 10 \mathrm{~s} \text { using to air pressure }\end{array}$ \\
\hline $\begin{array}{l}\text { All-Bond-Universal (ABU), Bisco Inc., Shaumburg, } \\
\text { IL., USA } \\
\text { Composition: 10-MDP, Dimethacrylate resins, HEMA, } \\
\text { Initiators, Ethanol, Water } \mathrm{pH}=3.2 \text { (ultra-mild) }\end{array}$ & $\begin{array}{l}\text { arate coats of adhesive, scrubbing the preparation } \\
\text { for } 10-15 \text { s per coat, } \\
\text { ess solvent by thoroughly air-drying with an air } \\
10 \text { s }\end{array}$ \\
\hline
\end{tabular}

in each water bath. Specimens were then further aged in demineralized water for six-months before testing.

\section{Failure mode and resin-dentin interface observation}

After bond strength testing, the de-bonded specimens were observed using SEM (JEOL JSM-5300, JEOL, Japan). To determine the mode of failure, low magnification was used to reveal the circumference of the bonded cylinders (40X). The fracture modes were classified as adhesive failure at the resin-dentin interface, cohesive failure in dentin, cohesive failure in resin, or mixed failure. To observe resin-dentin interface, a randomly selected representative specimen from each group was observed under higher magnification to view the resin-dentin interface.

\section{Statistical Analysis}

The statistical analysis was performed with IBM $^{\circledR}$ SPSS $^{\circledR}$ Statistics Version 20 for Windows. Numerical data were explored for normality using Kolmogorov-Smirnov (K-S) and Shapiro-Wilk tests. Descriptive statistics including the mean, standard deviation, maximum, minimum and confidence interval $(95 \% \mathrm{CI})$ of the $\mu \mathrm{SBS}$ testing were computed for each group. Two-way Analysis of
Variance (ANOVA) was used to study the effect of adhesive system, the effect of aging and their interaction on mean $\mu \mathrm{SBS}$. Bonferroni post-hoc test was used for pair-wise comparisons when ANOVA test is significant. The significance level was set at $\mathrm{P} \leq 0.05$. Fisher's exact test was used to compare between failure modes.

\section{RESULTS}

The K-S test indicated that $\mu$ SBS data were normally distributed and ANOVA demonstrated that significant differences existed between variables of the study $(p<0.05)$ Thus, the variables are dependent upon each other. The two-way ANOVA showed statistically significantly higher mean $\boldsymbol{\mu S B S}$ of PU adhesive (moderate $\mathrm{pH}$ group) than ABU adhesive (ultra-mild $\mathrm{pH}$ group): $25.63 \pm \mathbf{1 . 1 1}$ $\mathrm{MPa}$ and $18.83 \pm \mathbf{1 . 7 4}$ respectively, regardless of thermal-cycling and water storage (P-value $<0.001)$ as shown in figure (1). Moreover, there was a statistically significant decrease in mean $\boldsymbol{\mu S B S}$ after thermal-aging and water storage $(22.72 \pm \mathbf{3 . 1 2}$ and $21.74 \pm 4.29$ respectively) regardless of the adhesive system (P-value 0.018) as shown in figure (2).

Comparison between the two experimental groups revealed that PU adhesive showed 


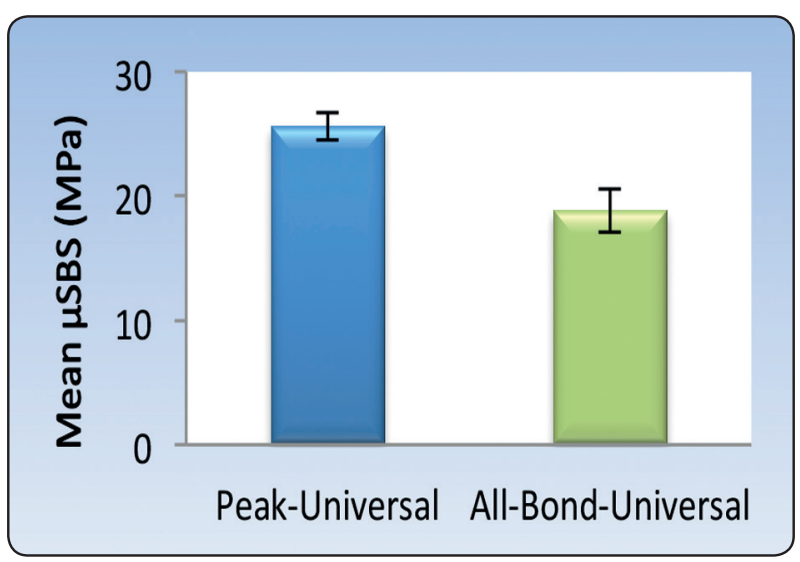

Fig. (1) Bar chart representing mean and standard deviation values for $\mu \mathrm{SBS}$ of the two adhesive systems regardless of thermal-cycling

statistically significantly higher mean $\boldsymbol{\mu S B S}$ than ABU adhesive $(25.48 \pm \mathbf{1 . 3}$ and $19.95 \pm \mathbf{1} . \mathbf{3 8}$ respectively) immediately and after aging. The comparison within PU adhesive showed no statistically significant change in $\boldsymbol{\mu S B S}$ immediately and after aging $(25.78 \pm 1.30$ and $25.78 \pm 0.93$ respectively) While ABU adhesive showed statistically significant reduction in mean $\boldsymbol{\mu S B S}$ after aging (19.95 \pm 1.38 and $17.70 \pm 1.3$ respectively) as shown in figure (3).

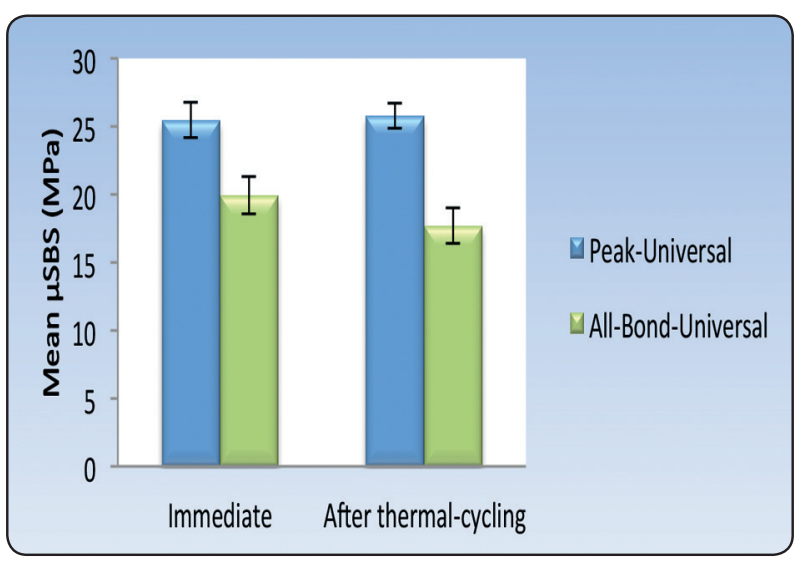

Fig. (3) Bar chart representing mean and standard deviation values for $\boldsymbol{\mu S B S}$ of the different interactions

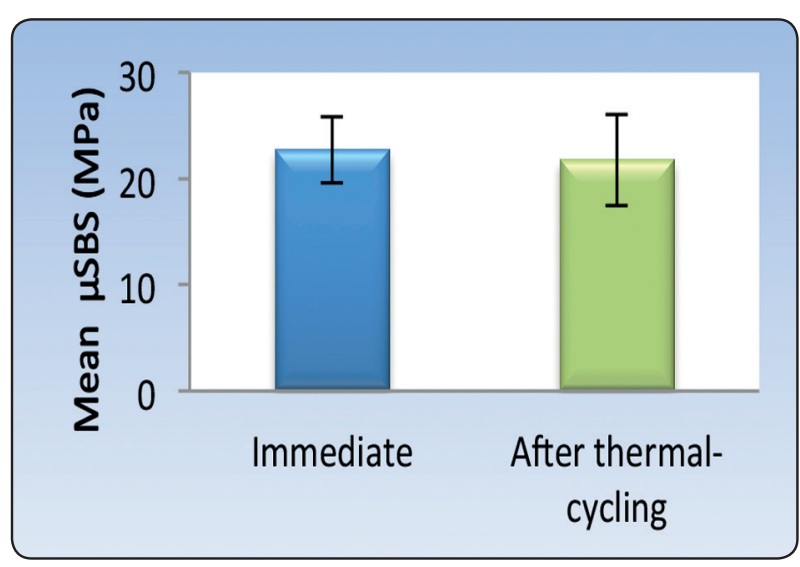

Fig. (2) Bar chart representing mean and standard deviation values for $\mu$ SBS immediately and after thermal-cycling regardless of adhesive system

\section{Failure mode and resin-dentin interface observation}

Microscopic examination of a dhesive joints revealed no significant difference in the frequency of the failure mode in the two tested groups, immediately or after aging $(\mathrm{p}=1)$. Yet, adhesive failure was the most prevalent type of failure mode after aging (71.4\% for PU group and $85.7 \%$ for ABU group). Lower percentage of cohesive failure were observed in both groups.

\section{SEM analysis of universal adhesives after aging}

Representative SEM images of failure mode and the bonded interface are depicted in figures 4-7. The micrograph of $\mathrm{ABU}$ at $\mathrm{x} 1500$ showed adhesive failure in the hybrid zone (Figure 4). At higher magnification (x7500), SEM revealed a thin hybrid zone (less than 1 micron). Some of the dentinal tubules were not filled with resin tags (Figure 5).

The micrograph of PU at x5000 showed adhesive failure with the resin-tags pulled out. At x2000, a thicker hybrid zone was observed and the dentinal tubules were filled with resin tag (Figure 8). 


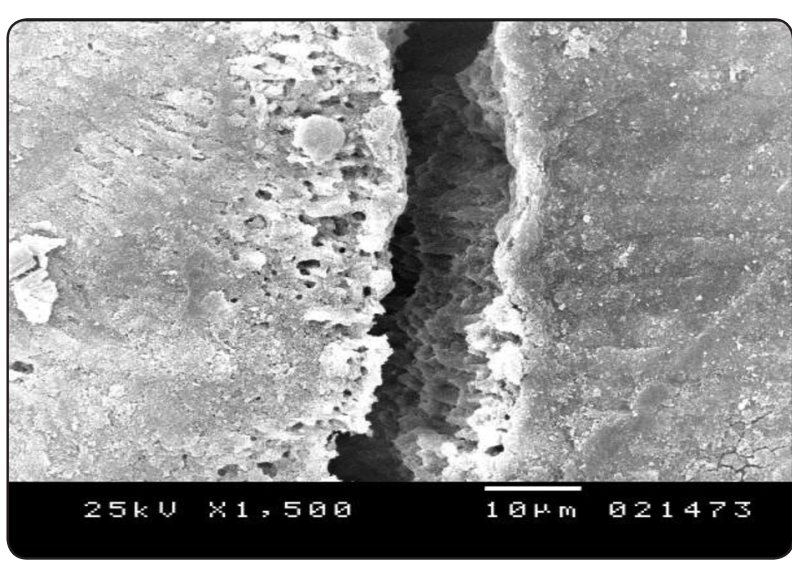

Fig. (4) SEM micrograph of ABU shows adhesive failure with obvious micro-gap at hybrid zone

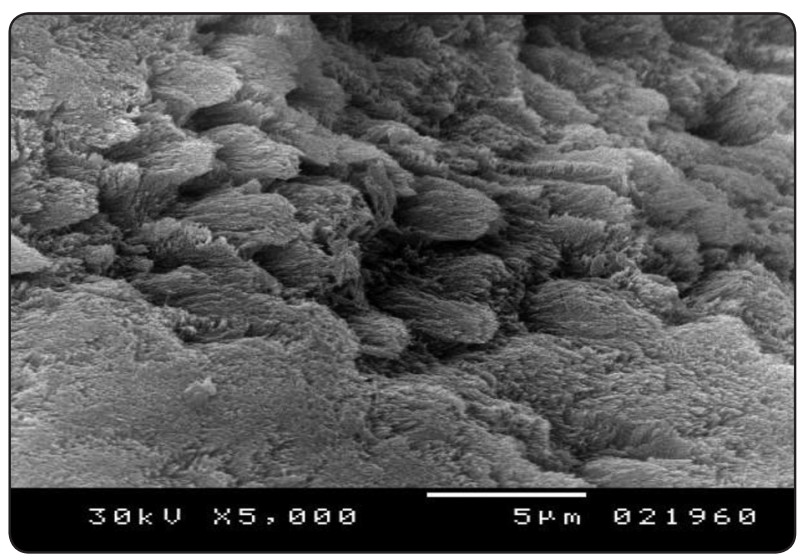

Fig. (6) SEM micrograph of PU at x5000, demonstrating adhesive failure showing resin tags pulled out.

\section{DISCUSSION}

In recent years, companies have launched several universal adhesives systems with diverse chemistry. Their composition varies in $\mathrm{pH}$ values, the type of solvent and resin monomers which may influence the characteristics and longevity of the adhesive layer that formed with dentin. Moreover, these materials can be used in a total- or a self-etch mode and were claimed by their manufacturers that no compromise in bonding performance with different substrates. Regarding the application mode, studies have shown that self-etch mode improved the bonding effectiveness of universal adhesives on dentin (Marchesi et al, 2014; Manfroi et al 2016).

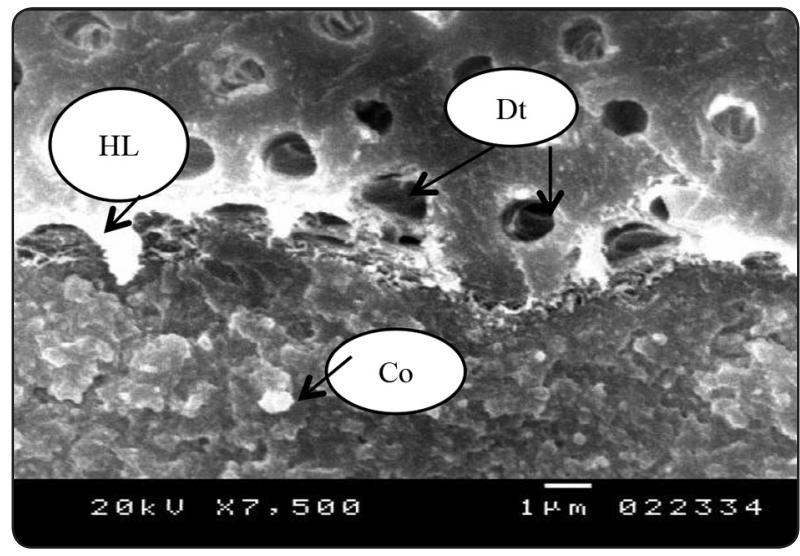

Fig. (5) SEM micrograph of ABU at the bonded interface. HL: hybrid layer, Dt: dentinal tubules, Co: composite resin

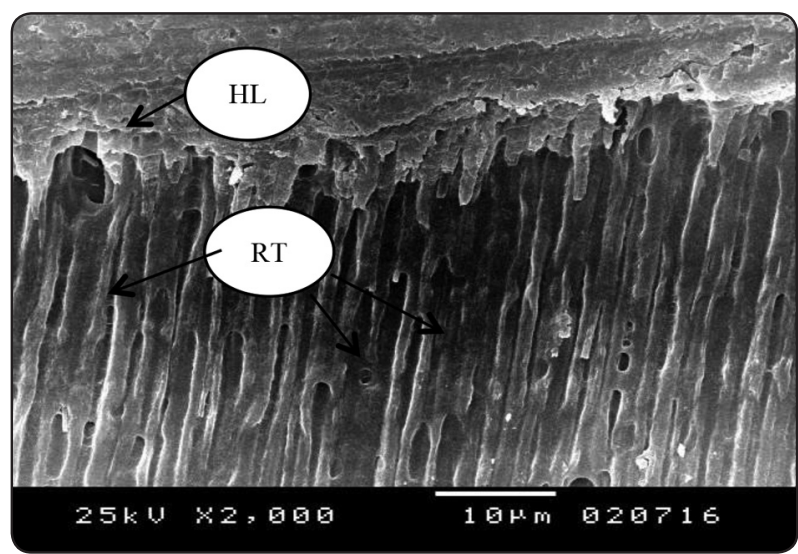

Fig. (7) SEM micrographs of PU: HL: hybrid layer, RT: resin tags

Based on these findings, longevity of two UAs, having different $\mathrm{pH}$ values were compared using self-etch mode.

The ultimate aim of in vitro degradation is to provide useful predictions of bond durability in real clinical situation. To this end, aging by thermalcycling and long-term water storage were selected in this study. As previously indicated in the literature, 10,000 thermal cycles are equivalent to one year of water storage (Kitasako et al, 2000; Kitasako et al, 2005; De Munck et al, 2005; Costa et al, 2017). The thermal stresses caused by discrepancies in the thermal expansion rates in the vicinity of the adhesive layer may change the mechanical properties of the 
adhesive layer and potentially result in accelerated bond degradation. Water sorption may not be a critical factor in thermal-cycling when the dwelling time is calculated. Adding long-term water storage to simulate hydrolytic degradation make it possible to consider how these degradation methods relate to the longevity of bonds in the real world (Powers \& Wataha 2013).

The results of this study demonstrated that the difference in bond strength between the two experimental groups were significant immediately and after aging with better bonding performance accredited to PU adhesive. Therefore, the null hypothesis that the type of the adhesive with different $\mathrm{pH}$ value has no influence on $\mu$ SBS was rejected. This disparity may be due to the difference in composition of the two adhesives. PU adhesive system is considered highly acidic $(\mathrm{pH}=1.2)$ and utilizes lower percentage ( $7.5 \mathrm{wt} . \%$ ) of ethyl-alcohol as a solvent, hence less susceptibility to be trapped by the water molecules within the hybrid zone. While ABU less acidic adhesive $(\mathrm{pH}=3.2)$ utilizes higher percentage (30-60 wt. \%) ethanol and water. The higher the percentage of the solvent, the more it is retained in the hybrid zone and the lower the possibility to form polymers with high reticulation. This may reduce the degree of monomer conversion and consequently, the $\mu$ SBS values.

It is documented that the smear layer acts as a true physical barrier against infiltration of monomers to be fully integrated with the dentin. The more the acidity of the functional monomer, the more the smear layer is removed and the more the ability to selectively demineralize the superficial dentin allowing monomer infiltration to create a well impregnated hybrid zone (Van Meerbeek et al 2003). PU adhesive contains functional monomers with higher acidic compared to $\mathrm{ABU}$ adhesive. This increase the amount of demineralization for micromechanical bonding and more collagen exposure for chemical bonding. This finding was supported by the ultrastructureal observation of the resin-dentin interface presented in the SEM images.
As a result, these differences may influence the characteristics of the formed adhesive layer. The results of this study was in accordance with Munoz et al (2013) who demonstrated better bonding performance to dentin with PU adhesive over other adhesive systems used as a function of $\boldsymbol{\mu}$ TBS.

Self-etch adhesives are known to be more hydrophilic in nature than etch-and-rinse adhesives. The high level of hydrophilicity may contribute to bond degradation over time. Aging tends to reduce the bond strength by water diffusion to the hybrid layer and degradation of demineralized collagen (Manso et al, 2009; Moon et al 2010; Pashley et al 2011). Despite the hydrophilicity of both adhesives used in the present study, aging by thermal-cycling and water storage significantly decreased the bond strength with ABU adhesive yet, this reduction was not significant with PU adhesive. Therefore, the null hypothesis that aging had no significant effect on bond strength was partly accepted for PU adhesive and rejected for $\mathrm{ABU}$ adhesive. The most interesting part in regard to PU adhesive is the delivery method. PU is applied in 2-steps in SE mode and it is delivered in 'syringe-in syringe' or 'jet mix syringe' and activated right before use. This may allow the manufacturers to incorporate less hydrophilic and more stable functional monomers. Additionally, the 2-step technique is thought to make the adhesive layer more hydrophobic and more stable (Breschi et al,2007). Using more hydrophilic one-step adhesive as ABU may result in a thinner adhesive layer that is more susceptible to polymerization inhibition by oxygen and create an adhesive layer that is more prone to hydrolysis (Reis et al 2008).

Bond degradation has been attributed to MMP enzymes in the dentin matrix, which become uncovered and activated both by acid-etchants and by acidic monomers used in adhesive systems that slowly degrade the collagen fibrils (Breschi et al, 2010; Pashley et al, 2011; Tjäderhane et al, 2013). MMPs are inhibited by protease inhibitors such as CHX through cation chelating mechanisms isolating metal ions such as calcium and zinc. Moreover, 
CHX has the potential to bind to both collagen and hydroxyapatite components in etched dentin (Zhang \& Kern, 2009; Ricci et al, 2010; Tjäderhane et al, 2013). In this study, CHX is incorporated within the composition of PU which could simultaneously inactivate MMPs until the adhesive is cured. This would increase the stability of resin-dentin adhesive and reduce collagen fibrils degradation overtime (Breschi et al, 2010; Tjäderhane et al, 2013) and may explain why there was no adverse effect of aging on resin-dentin bond strength with PU adhesive. In line with our results, a recent study reported no significant decline of TBS to dentin over time when PU was tested (Sadeghi et al 2017). Further investigation of effectiveness and durability of bonding to dentin of UAs containing $\mathrm{CHX}$ is recommended.

Another viable strategy for improving bond durability is the addition of 10-MDP (methacryloyloxydecyl dihydrogen phosphate). Studies have demonstrated that adhesives containing MDP allow for a stable chemical bond to dentin over the course of time (Reis et al 2009). This monomer forms a stable nano-layer together with a deposition of stable MDP-Ca salts at the adhesive interface (Toledano et al, 2007) which increases its bond strength. This wasn't in accordance to the results of our study. The presence of MDP in ABU adhesive couldn't prevent the reduction of bond strength by aging. Being a single-step self-etch adhesive with higher concentration of HEMA and lower concentration of MDP. This may allow HEMA to compete with MDP by bonding to the calcium of hydroxyapatite, thereby impairing the chemical bond of MDP to dentin and make the adhesive vulnerable to hydrolysis (Yoshida et al, 2012).

Although no significance in failure mode results, adhesive failure was predominant in all tested groups. It seems that the chemical bond formed by these systems has little influence on bond strength compared to micromechanical bond created by resin infiltration. The representative SEM images showed that the resin tags were pulled out off the dentinal tubules which may suggest that thermal stress is a significant factor in bond deterioration. In contrary, other investigations didn't prove that thermalcycling can influence bond strength (Wagner et al., 2014; Chen et al., 2015; Donmez et al., 2015). This controversy could be attributed to the variability in the methodology. All the above mentioned evidence may support the fact that the bonding behavior is material dependent and the diversity in the chemical composition of this category of adhesives may play a significant role in longevity of resin-dentin bonding.

\section{CONCLUSIONS}

Within the limitations of this in-vitro study, it can be concluded that non-simplified two-step universal adhesives may be preferred to achieve adhesive interfaces that are less prone to degradation and there ought to be no concerns about the longevity of dentin bond formed by more aggressive $\mathrm{pH}$ universal adhesive (Peak-Universal Bond) when self-etch mode is used. Additional in-vitro and in-vivo investigations are necessary to clarify the longevity of dentin bonding of universal adhesives with variable $\mathrm{pH}$ and diverse composition.

\section{Competing interests}

The authors declare that there is no conflict of interest regarding the publication of this paper.

\section{REFERENCES}

1. Breschi, L., Cadenaro, M., Antoniolli, F., Sauro, S., Biasotto, M., Prati, C., Tay, F. R. \& Di Lenarda, R. (2007). Polymerization kinetics of dental adhesives cured with LED: correlation between extent of conversion and permeability. Dental Materials, 23 (9), 1066-1072.

2. Breschi, L., Martin, P., Mazzoni, A., Nato, F., Carrilho, M., Tjäderhane, L., Visintini, E., Cadenaro, M., Tay, F. R., De Stefano Dorigo, E. \& Pashley, D. H. (2010). Use of a specific MMP-inhibitor (galardin) for preservation of hybrid layer. Dent Mater, 26 (6), 571-8.

3. Chen, C., Niu, L., Xie, H., Zhang, Z., Zhou, L., Jiao \& Tay, F. (2015). Bonding of universal adhesives to dentine-Old wine in new bottles? Journal of dentistry, 43(5), 525-536. 
4. Costa, D. M., Somacal, D. C., Borges, G. A., \& Spohr, A. M. (2017). Bond Capability of Universal Adhesive Systems to Dentin in Self-etch Mode after Short-term Storage and Cyclic Loading. The open dentistry journal, 11, 276-283.

5. De Munck, J., Van Landuyt, K., Peumans, M., Poitevin, A., Lambrechts, P., Braem, M. \& Van Meerbeek, B. (2005). A critical review of the durability of adhesion to tooth tissue: methods and results. J Dent Res, 84 (2), 118-132.

6. Donmez, N., Siso, S. H., Usumez, A., \& Bayrak, I. (2015). Effect of thermal cycling on micro-tensile bond strength of composite restorations bonded with multimode adhesive. Journal Of Adhesion Science \& Technology, 29(8), 731-739.

7. Farias, D. C., Caldeira de Andrada, M. A., Boushell, L. W., \& Walter, R. (2016). Assessment of the initial and aged dentin bond strength of universal adhesives. International Journal of Adhesion \& Adhesives, 70, 53-61.

8. Kitasako, Y., Burrow, M. F., Nikaido, T. \& Tagami, J. (2000). The influence of storage solution on dentin bond durability of resin cement. Dent Mater, 16 (1), 1-6.

9. Loguercio, A. D., Uceda-Gomez, N., Carrilho, M. R. \& Reis, A. (2005). Influence of specimen size and regional variation on long-term resin-dentin bond strength. Dent Mater, 21 (3), 224-231.

10. Manso, A. P., Bedran-Russo, A. K., Suh, B., Pashley, D. H., \& Carvalho R. M. (2009). Mechanical stability of adhesives under water storage. Dent Mater, 25 (6), 744-749.

11. Moon, P. C., Weaver, J., \& Brooks, C. N. (2010). Review of Matrix Metalloproteinases' Effect on the Hybrid Dentin Bond Layer Stability and Chlorhexidine Clinical Use to Prevent Bond Failure. The Open Dentistry Journal, 4, 147-152.

12. Mena-Serrano, A., Kose, C., De Paula, E. A., Tay, L. Y., Reis, A., Loguercio, A. D. \& Perdigao, J. (2013). A new universal simplified adhesive: 6-month clinical evaluation. Journal of Esthetic and Restorative Dentistry, 25 (1), 55-69.

13. Muñoz, M. A., Luque, I., Hass, V., Reis, A., Loguercio, A. D. \& Bombarda, N. H. (2013). Immediate bonding properties of universal adhesives to dentine. Journal of Dentistry, 41 (5), 404-411.

14. Marchesi, G., Frassetto, A., Mazzoni, A., Apolonio, F., Diolosà, M., Cadenaro, M., Di Lenarda, R., Pashley, D.H., Tay, F. \& Breschi, L. (2014). Adhesive performance of a multi-mode adhesive system: 1-year in vitro study. J Dent, 42(5), 603-612.
15. Matsui, N., Takagaki, T., Sadr, A., Ikeda, M., Ichinose, S., Nikaido, T. \& Tagami, J. (2015). The role of MDP in a bonding resin of a two-step self-etching adhesive system. Dent Mater J, 34 (2), 227-233.

16. Muñoz, M., Luque-Martinez, I., Malaquias, P., Hass, V., Reis, A., Campanha, N, \& Loguercio, A. (2015). In Vitro Longevity of Bonding Properties of Universal Adhesives to Dentin. Operative Dentistry, 40 (3), 282-292.

17. Manfroi, F. B., Marcondes, M. L., Somacal, D. C., Borges, G. A., Júnior, L. H. B., \& Spohr, A. M. (2016). Bond Strength of a Novel One Bottle Multi-mode Adhesive to Human Dentin After Six Months of Storage. The Open Dentistry Journal, 10, 268-277.

18. Nikaido, T., Ichikawa, C., Li, N., Takagaki, T., Sadr, A., Yoshida, Y., Suzuki, K. \& Tagami, J. (2011). Effect of functional monomers in all-in-adhesive systems on formation of enamel/dentin acid-base resistant zone. Dent Mater J, 30 (5), 576-582.

19. Pashley, D. H., Tay, F. R. \& Imazato, S. (2011). How to increase the durability of resin-dentin bonds. Compend Contin Educ Dent, 32 (7), 60-4.

20. Powers J. M. \& Wataha J. C. (2013). Dental materials: properties and manipulation chapter 2 properties of materials 14-25, 10th ed. Missouri:Mosby, Elsevier Inc., USA.

21. Poggio, C., Scribante, A., Della Zoppa, F., Colombo, M., Beltrami, R. and Chiesa, M. (2014). Shear bond strength of one-step self-etch adhesives to enamel: effect of acid pretreatment. Dent Traumatol, 30 (1), 43-48.

22. Perdigão, J., Swift, Edward J. (2015). Universal Adhesives. J Esthet Restor Dent, 27(6), 331-334.

23. Reis, A., de Carvalho Cardoso, P., Vieira, L. C., Baratieri, L. N., Grande, R. H. \& Loguercio, A. D. (2008). Effect of prolonged application times on the durability of resindentin bonds. Dental Materials, 24 (5), 639-644.

24. Reis, A., Leite, T. M., Matte, K., Michels, R., Amaral, R. C., Geraldeli, S. \& Loguercio, A. D. (2009). Improving clinical retention of one-step self-etching adhesive systems with an additional hydrophobic adhesive layer. Journal of the American Dental Association, 140 (7), 877-885.

25. Ricci, H. A., Sanabe, M. E., Costa, C. A. \& Hebling, J. (2010). Effect of chlorhexidine on bond strength of twostep etch-and-rinse adhesive systems to dentin of primary and permanent teeth. Am J Dent, 23 (3), 128-132. 
26. Sezinando, A. (2014). Looking for the ideal adhesivesA review. Rev Port Estomatol Med Dent Cir Maxilofac, 55(4), 194-206.

27. Sadeghi, M., Salehi, A. \& Roberts, M. W. (2017). Effect of Chlorhexidine Application on Dentin Bond Strength Durability of Two Etch-and-Rinse Adhesive versus a Universal Bond System. J Dent Oral Care Med, 3 (2), 202.

28. Toledano, M., Osorio, R., Osorio, E., Aguilera, F. S., Yamauti, M., Pashley, D. H. \& Tay, F. (2007). Durability of resin-dentin bonds: effects of direct/indirect exposure and storage media. Dental Materials, 23(7), 885-892.

29. Tjäderhane, L., Nascimento, F. D., Breschi, L., Mazzoni, A., Tersariol, I. L., Geraldeli, S., Tezvergil-Mutluay, A., Carrilho, M. R., Carvalho, R. M., Tay, F. R. \& Pashley, D. H. (2013). Optimizing dentin bond durability: control of collagen degradation by matrix metalloproteinases and cysteine cathepsins. Dent Mater, 29 (1), 116-135.

30. Van Meerbeek, B., De Munck, J., Yoshida, Y., Inoue, S.,
Vargas, M., Vijay, P., Van Landuyt, K., Lambrechts, P. \& Vanherle, G. (2003). Buonocore memorial lecture. Adhesion to enamel and dentin: current status and future challenges. Oper. Dent, 28 (3), 215-235.

31. Van Meerbeek, B., Yoshihara, K., Yoshida, Y., Mine, A., D., \& K., V. (2011). State of the art of self-etch adhesives. Dental Materials, 27 (1), 17-28.

32. Wagner, A., Wendler, M., Petschelt, A., Belli, R., \& Lohbauer, U. (2014). Bonding performance of universal adhesives in different etching modes. Journal Of Dentistry, 42(7), 800-807.

33. Yoshida, Y., Yoshihara, K., Nagaoka, N., Hayakawa, S., Torii, Y., Ogawa, T., Osaka, A. \& Meerbeek, B. V. (2012). Self- assembled nano-layering at the adhesive interface. Jour- nal of Dental Research, 91 (4), 376-381.

34. Zhang, S. C. \& Kern, M. (2009). The role of host-derived dentinal matrix metalloproteinases in reducing dentin bonding of resin adhesives. Int J Oral Sci, 1 (4), 163-176. 